\title{
Examining Museum Visits as Literacy Events: The role of mediators
}

\author{
KEIKO YASUKAWA, JACQUIE WIDIN, VIC SMITH, KAREN \\ RIVERA, MICHAEL VAN TIEL, PETER AUBUSSON, and \\ HELEN WHITTY
}

\begin{abstract}
Museum exhibitions are literacy rich environments. Visitors may engage with a range of texts including texts that constitute the exhibition objects themselves, those that convey information about the objects and those that instruct visitors about how the visitors are expected by the museum to navigate through the exhibition. The ways in which visitors engage with these diverse texts are important defining factors of the visitors' museum experience. For museums, understanding how texts in their exhibitions are influencing the museum experience, and the possibility of a museum experience for the broad public community is important in the fulfilment of their public mission as cultural and education institutions. In this paper, we adopt a view of literacy as a social practice, the perspective of New Literacy Studies (NLS), that offers a fruitful way for museums to consider the interactions between exhibition texts and their audiences. Such considerations, we argue, can inform museums' approaches to broadening their visitor demographics to more strongly fulfill their public mission. We show that the goals of NLS resonate with some of the goals of the New Museology movement in museum studies, a movement that aims to democratize what museums represent and how. From NLS, we employ the concept of a literacy event to describe an exhibition visit through a literacy lens, and the concept of a literacy mediator to examine the literacy event not exclusively as an individual event, but a collectively produced event. The paper draws on data on how the literacy events of two groups of 'nontraditional' visitor groups were mediated in an exhibition, and show how they reveal the range of different literacies that visitors need to negotiate in a museum exhibition.
\end{abstract}




\section{Introduction}

We will -

- Be an 'open' Museum - open to rich engagement, to new conversations about the collection and transparent in how we work and make decisions

- Offer visitors diverse ways to interact with the museum

- Present programs and exhibitions that reflect the spirit of the times and explore new ways to engage with audiences that may challenge, involve experimentation or generate controversy

- Support new kinds of learning and knowledge creation inside and outside the Museum

- Develop a comprehensive customer service ethos throughout the Museum

- Promote an internal culture of dialogue, experimentation, transparency and individual accountability

The above 'values' statement from a public museum in Sydney, Australia is not atypical of that which can be found on websites of other public museums. Public museums have a mission to be relevant and connected to the public, and aspire to engage a wide and diverse audience. The museum as an institution overtly embracing social and cultural diversity is, however, a relatively recent phenomenon, .

This paper examines museum exhibition visits through the lens of literacy to gain insights into how literacy practices interact with visitors' experiences in a museum exhibition. In particular, we focus on how such a lens can inform exhibition teams on ways of designing their exhibitions for a more socially and culturally diverse audience. For the purposes of this paper, we use the term 'traditional' visitor groups to refer to those groups of visitors who are strongly represented in the visitor demographics, and 'nontraditional' visitor groups to refer to those groups who are underrepresented, recognising that such characterisations are not unproblematic. In the next section, we provide a brief background to the emergence of the New Museology movement in museum studies which questions and attempts to redress the exclusive and elitist views about who should constitute the museum audience. We then show how the democratic goals of New Museology resonate with similar goals of the perspective on literacy that we take in this paper, namely New Literacy Studies (NLS). In the section that follows that, we introduce the research on which the paper is based: a pilot study in an exhibition targeting families with young children. We first explain the background to the research, and the range of data that 
was collected and the methods used, before focusing on the subset of data and findings for two groups of 'non-traditional' visitors who were recruited to participate in this research: a group of mothers and their young children from culturally and linguistically diverse supported playgroups, and a group of adult literacy learners. In the study of the museum experiences of these two groups, we describe how the literacy practices of the adult members were mediated by those who accompanied their visits. In the final section, we discuss what the observations of the literacy practices of the 'nontraditional' groups of visitors can tell us about the ways in which literacy interacts with visitors' experiences in an exhibition, and their implications for museums in their pursuit of a broader audience bpase.

\section{Museums and their relationships to the public}

The history of museums as cultural institutions is a story of cultural elitism and exclusion. Fleming (2002), writing from a British perspective, describes this as 'The Great Museum Conspiracy' where, over time, many museums became publicly funded, however remaining:

private and exclusive clubs, annexed by self-seeking interests because of the museum's cultural authority and power.

Contrary to at least some of the principles according to which most museums were created, museums have not been democratic, inclusive organisations, but agents of social exclusion, and not by accident but by design. (p. 213)

Fleming argues that in order to understand this 'conspiracy', one has to examine: who has run museums and how this leads museum staff to conceive their audience in their own image; what they contain, because 'what we collected cannot be dissociated from who did the collecting' (2002: 215); the way museums have been run, that is the politics within the museum as a workplace and the complacency of the dominant role taken by the curator in comparison to the roles of other staff such as the educational and marketing staff; and for whom museums have been run, and the ease with which the aim of running the museum for the 'public good' shifts to doing 'what's good for the public'(p. 218).

However, increasing political and economic pressures since the late decades of the twentieth century have led to some questioning of the older ethos (MacDonald 2006, Witcomb 2003). From an economic perspective, questions started to be asked about the size of the actual audience base relative to the potential audience base. Studies of the demographics of museum visitors became common, and what was found in many English- 
speaking countries was that museum visitors were predominantly the welleducated and economically privileged sections of the community (Australian Bureau of Statistics [ABS] 2009-10, Bennett 1994). This stands in contrast to the extract from the 'values' statement at the beginning of this paper. For example ABS (2010) statistics show that only about $20 \%$ of museum visitors in Australia were born in countries where English was not the main language; this compares with $25.5 \%$ of that same group in the total Australian population. Examining the statistics of highest educational attainment, of the population aged 15 years and over, those museum visitors who completed year 10 or below comprised approximately $15 \%$ of the population aged 15 years and over who visited museums; this compares with $25.5 \%$ of that same group in the total Australian population. Clearly a significant proportion of the Australian population is not visiting museums. Although statistics can only tell part of the story, and can only point to some of the factors that may explain non-participation, the disparities in participation rates related to factors such as language backgrounds and educational attainment levels as well as income levels and labour market status (ABS 2010) suggest that at least a closer examination is needed to understand if the non-participation is a conscious choice of resistance or a response to perceived or actual barriers. In particular, the museums themselves and the assumptions they make about who their visitors are, and what they assume visitors do in exhibitions can be interrogated and examined in relation to what are the actual practices of visitors in the exhibitions.

Politically, at least in the scholarly communities, questions about representation and cultural hegemony have arisen, especially in relation to historical and anthropological museums (Boast 2011, Clifford 1997) and to some extent in science museums (MacDonald 1996). Whose histories and cultures are being represented in museums, and through whose eyes? What is valued as knowledge and what is not; who decides? These are some of the central questions being raised in what has become known as the New Museology movement in museum studies.

The issue of privileging elite audiences is internationally recognised. Fleming (2002) and O'Neill (2002) describe initiatives in Scotland and England to create exhibitions that aimed to remove the exclusionary elements of museums. O'Neill (2002) discusses an exhibition on the history of Impressionism that cast this history in broader socio-historical contexts, including using mannequins of museum visitors in period costume to recreate how visitors in the late nineteenth century might have experienced the novel Impressionist art, and a reconstruction of the boat from which Monet had painted many scenes. He says that although the exhibition received a larger and wider audience, it angered critics who implied that 
'anyone who enjoyed this exhibition is somehow not a "good enough" person to be in an art gallery' (O'Neill 2002: 32). He and others (Fleming 2002, Grek 2006) have noted that many critics see the fundamental rethinking that is needed to engage critically with issues of social inclusion/exclusion as a form of 'dumbing down'. Furthermore, Grek (2006) draws attention to the different discourses that exist around the agenda for social inclusion, some of which simply adopt 'a deficit view of museum nongoers' rather than critically engaging 'in a public debate on the root causes of marginalisation and non-participation in museums and further afield' (p. 262). Both Grek (2006) and Ross (2004) also point to the need to understand the museums' interest and approach to social inclusion taking into account the political economy of museum work; in particular, there is a tension resulting from the pressures of funding that are trying to reshape the museum visitor from a citizen to a consumer. Thus there are complex social, cultural and economic agendas at play in the efforts of museums to widen their audience participation base. It is not the purpose of this paper to review the literature of the evolution of New Museology, but rather to point to its parallel emergence and concerns with New Literacy Studies (NLS) that have challenged orthodox notions of what constitutes literacy and being literate, and like New Museology, continue to evolve as a highly contested theoretical position (Munson 1997, Brandt and Clinton 2002, Witcomb 2003, Reder and Davila 2005, Street 2012).

\section{New Literacy Studies and New Museology}

NLS and New Museology (Vergo 1989) question hegemonies: in the first case, the nature of institutional definitions of what literacy is, and in the second, what museums should represent; over the ways in which individuals value and enact literacy in their everyday lives, and what the people whose stories are being told in museums value in their histories and lives, respectively. NLS encourages ethnographic approaches to learn about the literacy - or indeed literacies, of people in their everyday contexts, and similarly New Museology values listening to people from and in the communities, the stories that are unfolding and told and retold by the exhibition 'subjects' themselves. NLS and New Museology challenge the power traditionally held by educational policy makers and institutions - in the first case, to define what constitutes acceptable standards of literacy and what needs to be taught and learnt to achieve them, and in the second, to decide what constitutes valuable collections and how they should be interpreted for the audience.

Vergo's (1989) edited collection New Museology is considered one of the key texts that argued the need for a shift from the 'old' museology to the 
New Museology. Macdonald (2006) identifies from Vergo's volume three main points of departure from the 'old' museology:

The first is a call to understand the meanings of museum objects as situated and contextual rather than inherent. ...

... the second area to which the new museology drew attention

[is] namely: matters that might earlier have been seen as outside the remit of museology proper, such as commercialism and entertainment. ...

Linked with the first and the second is the third: how the museum and its exhibitions may be variously perceived, especially by those who visit. (2)

New Museology's resistance to separating the meaning of objects from how they are situated in their contexts, the questioning of what 'counts' as legitimate objects or exhibitions in a museum, and contemplation of the possibilities of a plurality of visitor experiences all resonate strongly with the ways in which NLS conceptualises literacy and numeracy as situated practices.

NLS also emerged in the last decades of the twentieth century as ethnographic studies of people's everyday practices started to challenge orthodox understandings of literacy as individual, cognitive acquisitions of skills (Heath 1983, Street 1984, Baynham 1995, Barton and Hamilton 1998, Barton 2007). Rather than assuming that there is any universally meaningful definition of what constitutes literacy, NLS scholars advocate a perspective of literacy as social practices:

As concrete activity, involving not just the objective facts of what people do with literacy, but also what they make of what they do, how they construct its value, the ideologies that surround it. (Baynham 1995: 53)

Thus, reading the different kinds of texts in a museum exhibition may be practices that are very unfamiliar and unvalued practices for people who, rightly or wrongly, assume that they would not be considered part of the intended visitor community of museums. NLS, in its focus on what people actually do, rather than on abstract notions of what they should be able to do, uncovers multiple literacies, rather than a single literacy within people's lives as they engage in different kinds of activities, but also different literacies around the 'same' everyday activity - such as reading letters and keeping track of the household finances, in their different communities. Here, with 
some reservation, we include numeracy and numeracies - that is the ways people use mathematical thinking and artefacts to make meaning, within our use of the terms literacy and literacies. While in some situations, naming an activity as a numeracy practice may be more appropriate, in everyday contexts, there is often a blurring of what constitutes literacy and what constitutes numeracy because language and mathematics as well as material artefacts are often all embedded in everyday activities.

In NLS the term literacy events is used to describe 'instances or occasions where uses of literacy plays a role' (Baynham 1995: 54). A literacy event can involve reading or writing or both, of many different kinds of texts, including visuals such as images. Critical to examining a literacy event, however, is not simply to describe the text that is being used and/or constructed, but to examine the social, cultural and political dynamics surrounding the event. Moreover, the often collective nature of the literacy event is an important focus. Baynham shows in his studies that a literacy mediator is often crucial to the accomplishment of a literacy task, that is 'a person who makes his or her literacy skills available to others, on a formal or informal basis, for them to accomplish specific literacy purposes' (1995: 5960). Thus, he cites an example from his own study where he acted as a literacy mediator in London for an immigrant woman from Morocco who needed the assistance of Baynham's English literacy skills to read and produce a response to a letter that she had received from a government department.

From a NLS perspective, visits to a museum exhibition can be viewed as a literacy event. From the point of entry into the museum and then to a specific exhibition space, visitors typically encounter texts and diagrams intended to guide their navigation through the exhibition. They would encounter labels on the exhibited objects providing information and interpretations of the significance of the objects and they may also encounter signage about what they can/ cannot do or touch. Where there are interactive objects, there may be written instructions about what to do. In some exhibitions, the objects themselves are texts - historical manuscripts, letters, posters, and so on. Veteran museum visitors know that successfully negotiating an exhibition visit, however, does not entail intensive viewing of all the exhibition objects and reading and comprehending all of the texts in the exhibition; they know that they can pick and choose what to read, and that they can decide how they would make their selections. Those who are less experienced visitors and who may not relate in predictable ways to the normative notions of literacy, may not naturally assume this kind of agency were they to arrive at an exhibition on their own. What occurs for an individual in a particular literacy event, and what they make of it and its 
value is influenced by how they relate the event to the broader social context of the event, how they themselves value the event as a literacy activity, and how they perceive others would value it (Baynham 1995). A central concept in NLS is that of literacy as social practice, that is, as an activity that cannot be understood in isolation of the political, socio-cultural and historical context in which it occurs. The literacy practices of experienced museum visitors are acquired and learnt, even if informally rather than formally. There may be an important role for literacy mediators that can assist novice visitors to learn these practices.

Another insight from a NLS perspective on literacy practices in exhibitions is provided by Hackett (2012) in her study of children's meaning making and movement in family oriented exhibitions. She examines how the experience of the exhibition is a multi-modal communicative practice that is shaped by the spatial configurations of the objects in the exhibition, but as well as that, the children's movements within the space - 'zigging and zooming' (p. 14), as one of her young research participants described her actions in the exhibition. Thus for family groups that visit exhibitions, the adults' literacy practices in the exhibitions may be strongly influenced by their children's movements within the exhibition space. Hackett notes, the trajectory is traversed sometimes quickly and sometimes slowly, and in some cases, the trajectory loops back to the same object multiple times. Thus capturing the literacy practices in museums ideally would involve capturing in some way, their spatial and temporal influences.

We acknowledge that NLS researchers such as Pahl and Rowsell (2010) have made connections between objects of exhibitions and literacy and developed a notion of artifactual critical literacies. While their work is not unrelated to this current study, it is more concerned with developing frameworks for literacy education where the everyday artefacts of learners can be seen as resources for literacy learning. This differs from our interest in the literacy practices of visitors to museum exhibitions and the expected or intended practices engendered by the museum.

Finally, although the museum studies literature is limited in studies focusing explicitly and specifically on literacy in museums as social practice, Bennett (2006) writes about a related concern:

the respects in which the functioning of museums as civic institutions has operated through specific regimes of vision which, informing both the manner in which things are arranged to be seen and the broader visual environment conditioning practices of looking give rise to particular forms of 'civic seeing' in which the civic lessons embodied in those arrangements are to be seen, understood, and performed by 
the museum's visitors. Or at least those visitors who are included in the museum's civic address. (285)

He (Bennett 2006) shows in his study that these 'regimes of vision' have changed from early modernity to the present. From a NLS perspective, this suggests that the literacy practices expected of visitors, and those practices that visitors demonstrate, both need to be understood as historically contingent.

\section{Extending the museum family: the study and research method}

The study on which this paper is based originated at a conference for adult literacy and numeracy practitioners in Sydney, Australia. An educational consultant at a public museum and a member of our research team presented her work on a numeracy exhibition for children. The adult literacy and numeracy practitioners attending her session asked what type of learning resources the museum provided for adult numeracy and literacy learners - a question that triggered our thinking and led to the current study to explore how museums as cultural institutions understand how (or if) museums consider literacy as a factor in exhibition design for engaging visitors, particularly 'non-traditional' visitor groups.

A public museum in a capital city in Australia expressed an interest in partnering with the university in which four of the authors work, to pursue a study about the museum's conception of the relationship between literacy and visitor engagement. The museum had recently opened an exhibition targeting families with young children (aged two to five years) which presented the story of a popular internationally known children's entertainment group, the Whirly Gigs (pseudonym). This exhibition was chosen as the site for this study because of the long exhibition duration and the museum's interest in expanding their family audience and fulfilling their values statement, particularly in relation to expanding the diversity of their audience base. While the study did observe both family groups and unaccompanied adults, its focus was primarily on the literacy practices of the adults of these visitor groups in the exhibition.

We discuss the complexity of the visitor experience below. It is particularly complex given the multimodal exhibition environment, a space we need to take account of in our conceptualisation of literacy in the museum context (Dicks, Soyinka and Coffee 2006). The exhibition contained multiple forms of modality within its exhibitions. The various modes, for example, the video projections, physical interactives such as cutting up wooden blocks, posters, written texts and the layout of the 
exhibition, allow certain meanings to be made and communicated in the exhibition. Hence, as researchers we wanted to embrace the complexities of the visitor experience and adopt an approach, informed by Dicks et al (2006) and similar to Allen et al (2007 cited in Barrett 2012: 128), which recognises the multiple realities of this experience. We collected a number of different types of data in order to examine the issue of literacy and visitor engagement from a range of perspectives, and to explore the museum's intended 'regimes of vision' in relation to the actual literacy practices of different groups of visitors. We were aware of the lack of studies which provide detail of what visitors actually do in museums and we were keen to capture the behaviours of 'traditional' and 'non-traditional' visitors to our research site. Hence, there were six sets of data, collected using different methods.

1. The first set of data consisted of more than 12 hours of researchers' observations of what adult visitors who came of their own volition - that is, visitors not specifically recruited to participate in the study - did in the exhibition. Each researcher followed and observed one visitor at a time, from the point of entry into the exhibition through to the point of exit. Field notes consisted of observational data recorded on paper or into a digital recorder as they followed the visitor.

2. A second set of data consisted of 30 intercept exit interviews with adult visitors who like in the first data set, came to the exhibition of their own volition. These interviews were conducted in an area close to the exit point of the exhibition. Visitors were asked a structured set of questions including what they did in the exhibition and if and how they had engaged with print based, audio and interactive objects.

3. The third set of data consisted of responses to an online survey. An online survey was developed with similar questions to the intercept interviews, and the link to the survey was sent out to a group of online enthusiasts of the children's entertainment group and exhibition; 154 people responded.

4. The fourth set of data was provided by the museum. The researchers were given access to a summary of the 1,113 responses to a visitor exit survey conducted by the museum, which were completed on paper by visitors to this exhibition.

5. Individual interviews that were conducted with the design team of the exhibition, constituted the fifth data set. This included interviews with the curator, the exhibition editor, the specialist in interactive technology and the designer. The main purpose of these interviews was to understand the role of the design team in the development of the exhibition and the ways in which they gave consideration to literacy as part of their design. 
6. A sixth set of data was generated from observations and focus groups of two groups of visitors who were specifically recruited for this study, and for whom arrangements were made to visit the exhibition at an agreed time. In this paper, we refer to these visitor groups as 'non-traditional' visitor groups for reasons that will be explained. In the focus groups, the visitors were asked about their expectations of the exhibitions, their prior experiences of museums, what they 'read' in the exhibition, and broadly how they found the exhibition.

The above sets of data provide a multileveled picture of the experiences of and reflections on visits to the exhibition as well as the thinking behind the exhibition design. The first five sets of data suggest much about museums and literacy, and the sociocultural role the institution plays in conceptualising the visitors for whom the museum traditionally caters; we also learn much about visitor behaviour and expectations in regards to this particular exhibition. However, in this paper we focus primarily on what the sixth data set can tell us: the experiences of the recruited research participants as this tells a particular story about a literacy event for groups of people that statistics (ABS 2010) suggest would not necessarily visit a museum; these are the 'non-traditional' visitor groups.

Based on the demographic data of museum visitors (ABS 2010) that suggests language backgrounds and educational attainment are negatively correlated with museum attendance, two groups who would fall into the 'non-traditional' museum visitor groups were identified for research purposes: parents (and their young children) from culturally and linguistically diverse communities participating in supported playgroups which are designed for families who had difficulties accessing mainstream playgroups, and a group of adult literacy learners from an adult basic education program. Separate arrangements were made for those interested from each of these groups to visit the exhibition, and to participate in a focus group interview after spending approximately 45 minutes in the exhibition. Eight mothers from the playgroup arrived with their young children (ten children in total), while nineteen adult literacy learners arrived with three of their teachers. Both groups were briefed on the aims of the research and what their involvement would entail prior to their museum visit. In the case of the parents in the playgroup, two of the researchers visited the playgroup centres and talked to the mothers, and in the case of the adult literacy learners, two of the researchers briefed the head teacher and a classroom teacher, who then briefed and prepared the students and two other teachers. A one-page information sheet about the project was provided, and a consent form was explained and signed by all the adult focus group participants.

Ethics approval was obtained from the university in which the authors work. 
This paper focuses on the literacy events of these two 'non-traditional' groups of visitors: the mothers from the supported playgroup and the adult literacy learners. Observations of their literacy practices in the exhibition are examined in relation to the findings from the other data sources.

\section{Mediating literacy events in a popular culture exhibition \\ Ghildren as mediators}

The first of our 'non-traditional' visitor groups consisted of eight mothers who were members of supported playgroups accompanied by their young children. The majority of participants were recruited from a group consisting mainly of Indonesian mothers and children that met once a week at a supported playgroup. One mother and her two children were recruited from another playgroup that met at a different centre where there was a greater diversity of language and culture groups. When two of the researchers visited the two playgroups to explain what the project was about, and to invite them to be part of the project, all of the mothers in the Indonesian group were familiar with the Whirly Gigs and their iconic position in Australian popular culture. They immediately expressed interest, and one of the mothers offered to organise the group for the excursion to the museum. In the second more culturally and linguistically diverse playgroup, several of the mothers indicated that they would have to check with their husbands first, or that they could only come on weekends when their husbands could come as well. Ultimately, only one mother and her children were able to take part from this second group.

Observing the mothers and children in the exhibition, the behaviour of the mothers was strongly influenced by how their children wanted to engage with the exhibition. Although coming as a group meant that some of the mothers helped each other to keep an eye on where the children were and what they were doing, the mothers' visual gaze and engagement with the objects of the exhibition appeared to be determined by what the children were engaged with or what they needed assistance in negotiating, along with a focus on managing children's behaviour. Similar to what Hackett (2012) observed, there was much 'zigging and zooming' in the children's trajectories in the exhibition space. Mothers engaged in helping children to prepare a 'postcard' for one of the characters of the entertainment group by using stamps on blank postcards, or by making flowers using crepe paper and wire for another character of the group. The latter activity did require reading a set of instructions with visual cues of the steps involved. However, there appeared to be little adult engagement with the large information based displays including historical artefacts such as newspaper coverage of the group's international tours and text based information about the group's charity work. The exhibition included labels 
that the exhibition editor explained were intended for adults in the family group to read to the child, and these labels were intended to be identified by their coloured borders. However, the significance of these coloured borders was elusive to this visitor group, and there was no noticeable engagement with these labels among this visitor group.

The level of engagement of these family groups with the exhibition texts was not dissimilar with what we had noticed among the family groups who came of their own volition. However, with this 'non-traditional' visitor group, there was a high level of interaction between the mothers because of the group nature of their visit. A common activity of all family visitors in this exhibition was the photographing of the children engaging with the different objects and activities. One noticeable difference between the mothers of this group, and the adults accompanying children in the groups who came of their own volition, was that in the latter group, the majority of the adults we observed were spending the time not occupied with their children texting on their mobile phones. The use of the mobile phone in the exhibition, except for taking photographs of their children, was not observed among the mothers from the supported playgroup. It is possible, however, that this behaviour was due to the researchers' presence in the exhibition area and our role in facilitating the visit.

During the focus group discussion with the mothers immediately after the exhibition visit, many of the mothers were very vocal in their criticisms of the exhibition design. While they all said that the exhibition was highly enjoyable for the children, they raised a number of concerns. A comment they made in response to our first question about their expectation of activities in the exhibition was that they had expected a photo-booth where the children could have their photos taken, preferably for free, with a life size picture of the members of the entertainment group in the background several said that another museum they had visited had such a set-up. A second concern they raised was the lack of explicit directions about how the visitors were to navigate through the exhibition - they wanted to have a map, which one of the mothers had managed to find and pick up but which others had missed. A third unanimous, and adamantly made comment was that they had expected there to be more computer interactives in the exhibition. A fourth comment was that they had wanted stronger moral messages for the children in the exhibition, such as messages about eating well and good behaviour. The songs and activities that this entertainment group created, and which were part of the exhibition, have educative messages; for example, there is an activity and song 'yummy and healthy' (pseudonym) to promote colourful fruit in the children's diet, and a song about 'our bright yellow bus' about road safety. However, the mothers felt 
there should have been more and stronger messages conveyed through the objects in the exhibition.

The mothers in this 'non-traditional' visitor group came with clear expectations, some of which were not adequately met. They came to the visit to provide an experience for their children with strong beliefs about what the nature of that experience should be, at least partly shaped by their prior knowledge of the Whirly Gigs. Their visit as a literacy event was strongly mediated by both what the children wanted to see and do, and what they wanted their children to see and do. From observing their behaviour, it is possible to identify their children and their interests and movements in the exhibition space as 'barriers' to the mothers' own engagement with the written texts in the exhibition - those labels that were intended to facilitate a conversation between the adult and the child, archival texts and other information intended for the adult audience. However, it is also possible that for the adults in this group, and possibly for some of the adults in the group of visitors who visited of their own volition, the exhibition simply did not appeal to their interests.

\section{Adult literacy teachers as mediators}

The second 'non-traditional' visitor group consisted of 19 adult literacy learners from an adult basic education program in a local college. The head teacher of the section explained that several of the adult literacy classes were focussing on Australian social history at the time that we wanted to organise their visit to the exhibition and it was agreed that the exhibition could form a relevant experience for this curriculum focus. The three men and sixteen women visited the museum with three teachers who had been working with them. The adult literacy learners were a diverse group from different cultural and linguistic backgrounds and while some were recent migrants to Australia, others were long term residents with varying lengths of time since arriving in Australia and one or two were born in Australia.

There was a range of different kinds of engagement with the exhibition by members of this group. Most of the learners moved through the exhibition in small groups with a teacher who would point to different objects or texts, and engage in conversations around them. Two of the learners - one Australian born, and another a recent migrant from Africa moved freely through and spent time at the holographic performance space where visitors would watch three dimensional images of the group members singing and performing. The two learners got involved without any mediation from the teachers, as young children did, in dancing to the songs. Other learners got involved with the teachers in making flowers, as did the 
mothers and young children in the previous 'non-traditional' visitor group. A number of students showed a high level of curiosity in a 'garden' just outside the exhibition space. The garden is created through digital lighting effects on the floor where visitors could see fish swimming in a flowing stream, and walk around the garden path. Several of the students watched the creation of different effects such as shimmering water, but it was only after one of the teachers walked in and stepped through the garden path and encouraged the students to also walk across, that any of the learners ventured to walk into the garden.

In the focus group immediately following a visit of just under an hour in the exhibition, the learners were asked about their prior museum experiences and their reaction to the exhibition they had just visited. Some of the learners needed encouragement from the teachers to express their views. Only one of the learners had visited this particular museum previously and had not visited the exhibition she had just seen. A few of the learners said that they had been to one of the other public museums in the city with their children or grandchildren, a museum that primarily focuses on natural history.

When asked what they had expected to experience in the exhibition they had just visited, one of the learners said that she had expected something similar to what she had experienced in the natural history museum: 'like dinosaurs and pictures ... but come here, it's different'. Prompted to elaborate on the difference, one learner said that there was 'lots for children, so you could just do what children normally do ... dancing', and another noticed 'powerful colours' and said 'I feel good'. One of the more recently arrived migrant learners compared the exhibition to museum exhibitions in her home country and said that 'this one, different to museums in my own country everything old, traditional, old paintings ... everything that's old - old equipment, yeah paintings ... this big difference'.

Only the Australian born students and other learners with young children had known about the Whirly Gigs prior to coming to this exhibition. One of the Australian born students said that he had collected vinyl records of a previous group featuring these particular musicians, and was interested to see some of these record covers displayed in the exhibition.

The learners showed some interest in knowing more about the focus and history of the museum, and why it was so different to the 'other' natural history museum. The teachers and the researchers shared what they knew about the industrial history of the building in which the museum is housed, and the contemporary focus on science, technology and social history that this museum had, which was different to the historical focus of the other museum. 
There were varied responses about what was available to read in the exhibition. Two of the learners said that some of the labels were 'difficult' and there were 'some I can't understand', while another said that it was 'interesting to read [the labels], and know about the things'. One of their teachers said that he had explained the meaning of the word 'board shorts' to one of the students for whom English was an additional language. The student did not know that 'board shorts' was a common Australian term derived from combining the words 'surf boards' and 'shorts'. This word had a special significance in the exhibition because the members of the Whirly Gigs wore colourful board shorts in their early performances. Several of the students acknowledged the value of having their teachers with them to help them with the meaning and purposes of the texts as well as unfamiliar words.

The learners were given free passes for another visit, and several of the students enthusiastically said they would definitely come back to this exhibition, some with their children.

\section{Discussion and conclusion}

The participation of the family group from the supported playgroups, and the adult literacy classes allowed us to observe and examine the role of mediators in the visit to the museum. However, the literacy experiences of each of the 'non-traditional' visitor groups in the exhibition were very differently mediated.

For the groups of mothers who came with their children of their own volition, and the 'non-traditional' families from the playgroup, their visit the literacy event - was shaped largely by what their children wanted to do and what they expected the exhibition and the museum to provide for the visitors to enhance the value of the visit for their children. Observations of their behaviour suggest that what most of the mothers read in the exhibition was mediated by their children, based on what the children needed or wanted to know, for example, instructions of how to make the flowers. Several of the mothers from the 'non-traditional' visitor groups had come with expectations of what to see in the exhibition, such as a map of the exhibition space, and signage for a photo-booth; these were expectations formed from their earlier visits to other museums where they had been provided with a map, and had access to a photo-booth. Several of the same group of mothers were also seeking stronger 'moral' messages or lessons to be conveyed to the children, and were disappointed.

The expectations and behaviours of the families from the playgroup were very similar to those exhibited in observations and interviews of other family visitor groups, except for the playgroup mothers' expectations of a stronger moral message, a photo-booth and more interactives. Most of the visitors who were not recruited as 'non-traditional' visitors also said they 
were there for their children's entertainment and that they did not do a lot of reading for themselves because this was not the purpose of the visit and their responsibilities for their children would not have allowed that. For many of the adults of all of the family groups who were observed, the children had a significant role in defining the spatial boundaries of adults' engagement in the exhibition, and consequently their literacy practices.

What we observed in the adult literacy learners' visit to the exhibition was different in many ways to the visit of the families from the playgroup. But what many, though not all of the learners, saw in the exhibition was also mediated - in this case, by their literacy teachers who pointed out different objects and texts to the students. Unlike the mothers in the playgroup, the role of the mediator involved encouraging and helping the adult learners' reading and sense-making of what they were reading, including decoding words like 'board shorts', as well as the history and significance of the Whirly Gigs. Some of the learners waited to see the teachers interacting with an object and receiving signals and encouragement such as 'yes, it's $O K$, you are meant to walk across the garden' before they did so themselves. The focus group discussion revealed that several of the students had come with a preconception of museums as places where visitors look at objects and perhaps read texts behind glass cases; they were less familiar with exhibitions where they could play an active part, but said they liked the new kind of museum experience. Also, unlike the first group, the literacy learners showed an interest in knowing more about the museum itself, the significance of its name and history, and the reason why it felt so different to the more traditional natural history museums that some of the group had visited. For these learners, the visit was not only learning about the entertainment group that was the focus of the exhibition, but also about the different museums in the city - the social history of their city.

It is also important to note the experience of the mothers and children from the supported playgroup who were not able to participate. The mothers in this group had said either that they had to discuss the invitation with their husbands first, or that they could only come on a Sunday when their husbands could also come. Thus a museum visit for these mothers was assumed to have some level of mediation from their husband, and because the visit could not be scheduled on days when their husbands were free, we did not have the opportunity to observe how they might have negotiated the visit.

This study was undertaken as a pilot to begin to investigate how literacy practices influence visitor experience in a museum exhibition. The observations and interviews with the two 'non-traditional' visitor groups 
revealed several kinds of literacies that influence the kind of engagement visitors might have in a museum exhibition. They include:

- Reading the intended purpose of the exhibition, for example, is it aimed to tell a history of some aspect of popular culture; is it to educate children on good behaviour, right and wrong; is it a place of amusement and entertainment?

- Reading the intended audience, for example, is it for children, for adults, or both; are different parts of the exhibition intended for different audiences?

- Decoding the labels, for example, what does this word mean; does this word have a special meaning in this exhibition context or is it part of the general vocabulary?

- Reading the 'regime of vision', for example, is the exhibition designed for the visitor to look at everything in any particular order; are visitors encouraged to read the labels to absorb authoritative information or to see it as a trigger for a conversation with a fellow visitor; can I touch this object?

- Reading the museum as a cultural institution, for example, why is this museum exhibiting these kinds of objects rather than something else; why does this museum feel so different to the other museum in town?

Not all visitors would need or want to have a mediator to help them negotiate all of these literacies. However, for museums that are trying to extend their audience base, analysing the literacies that are involved for visitors in any exhibition may usefully inform how they design and market their exhibitions because in the very design and marketing of the exhibition, they are producing or reproducing particular literacy practices. The museum experience can be exclusive. There is a need to further explore literacies and perceptions of what literacies are important and valued by museum-goers, museum non-goes, exhibition designers and developers. Thinking of a museum visit in terms of literacy events may enable us to imagine museum experiences in new ways that enable dialogue with, challenge and provoke a more extensive and inclusive audience.

\section{References}

Australian Bureau of Statistics (2010) Attendance at Selected Cultural Venues and Events, Australia, 2009-10 (cat. no. 4114.0), Australian Bureau of Statistics, Canberra.

Barrett, J (2012) Museums and the Public Sphere, Wiley-Blackwell, West Sussex. 
Barton, D (2007) Literacy: An introduction to the ecology of written language, $2^{\text {nd }} \mathrm{ed}$, Blackwell, Oxford.

Barton, D and Hamilton, M (1998) Local Literacies: Reading and writing in one community, Routledge, London \& New York.

Baynham, M (1995) Literacy Practices: Investigating literacy in social context, Longman, London \& New York.

Bennet, T (1994) The Reluctant Museum Visitor: A Study of Non-Goers ...to History Museums ... and Art Galleries, Australia Council, Sydney.

Bennett, T (2006) 'Civic Seeing: Museums and the Organisation of Vision', in MacDonald, S (ed), Companion to Museum Studies, Wiley-Blackwell, Maiden, MA, 263-281.

Boast, R (2011) Neocolonial Collaboration: Museum as contact zone revisited, Museum Anthropology, vol 34, no 1, 56-70.

Brandt, D and Clinton, K (2002) 'Limits of the Local: Expanding perspectives on literacy as a social practice', Fournal of Literacy Research, 34, pp 337-356.

Clifford, J (1997) Routes: Travel and translations in the late twentieth century, Harvard University Press, Cambridge MA.

Dicks, B, Soyinka, B and Coffee, A (2006), Multimodal ethnograhpy, Qualitative Research, vol 6, no 1, 77-96.

Fleming, D (2002) Positioning the Museum for Social Inclusion, in Sandell, R (ed), Museums, Society, Inequality, Routledge, London \& New York, pp 213-224.

Grek, S (2006) Museums and the Unbearable Lightness of Inclusion, in Antikainen, A, Harinen, P and Torres, CA (Eds), In from the Margins: Adult education, work and civil society, Sense Publishers, Rotterdam, pp 253-264.

Hackett, A (2012) Zigging and Zooming All Over the Place: Young children's meaning making and movement in the museum, Journal of Early Childhood Literacy, accessed 20 April, 2013 at http://ecl.sagepub.com/context/early/2012/08/08/146879841245 3730.

Heath, SB (1983) Ways with Words, Cambridge University Press, Cambridge, UK.

MacDonald, S (1995) 'Consuming Science: Public Knowledge and the Dispersed Politics of Reception among Museum Visitors', Media, Culture E Society, 17, pp 13-29.

MacDonald, S (1996) 'Authorising Science: Public Understanding of Science in Museums', in A. Irwin \& B. Wynne (Eds), Misunderstanding Science: The Public Reconstruction of Science and Technology, Cambridge University Press, Cambridge, UK. 
MacDonald, S (2006) 'Expanding Museum Studies: An Introduction', in MacDonald, S (ed), Companion to Museum Studies, Wiley-Blackwell, Maiden, MA, pp 1-12.

Munson, L (1997) 'The New Museology', Public Interest, Spring, 127, 60-70.

O'Neill, M (2002) 'The Good Enough Visitor', in R. Sandell (ed), Museums, Society, Inequality, Routledge, London \& New York, 24-40.

Pahl, K and Rowsell, J (2010) Artifactual Literacies: Every object tells a story, Teachers College Press, New York.

Reder, S and Davila, E (2005) 'Context and Literacy Practices', in Annual Review of Applied Linguistics, 25, pp 170-187.

Ross, M (2004) 'Interpreting the New Museology', Museum and Society, vol 2, no 2, pp 84-103.

Street, B (1984) Literacy in Theory and Practice, Cambridge University Press, Cambridge, UK \& New York.

Street, B (2012) 'New Literacy Studies', in Grenfell, M, Bloome, D, Hardy, C, Pahl, K, Rowsell, J and Street, B (Eds), Language, Ethnography, and Education: Bridging New Literacy Studies and Bourdieu, Routledge, New York \& London, pp 27-49.

Vergo, P (ed) (1989) The New Museology, Reaktion Books, London.

Witcomb, A (2003) Re-Imaging the Museum: Beyond the Mausoleum, Routledge, London \& New York. 